\title{
Exploring of drug leads from diversity-oriented Michael-acceptor library derived from natural products
}

\author{
Xu Deng, ${ }^{\text {a,b }}$ Ling-Mei Kong, ${ }^{\text {a,b }}$ Yu ZhaO, ${ }^{\mathrm{a}}$ Juan He, ${ }^{\mathrm{a}}$ Li-Yan Peng, ${ }^{\mathrm{a}}$ Yan LI, ${ }^{\mathrm{a}, *}$ and Qin-Shi ZHaO ${ }^{\mathrm{a}, *}$ \\ ${ }^{a}$ State Key Laboratory of Phytochemistry and Plant Resources in West China, Kunming Institute of Botany, Chinese \\ Academy of Sciences, Kunming 650201, China \\ ${ }^{\mathrm{b}}$ Graduate University of Chinese Academy of Sciences, Beijing 100049, China
}

Received 19 August 2012; Accepted 12 September 2012

(C) The Author(s) 2012. This article is published with open access at Springerlink.com

\begin{abstract}
A potential strategy for drug lead identification and in-active natural products re-discovery is elaborated. Starting from fifteen structurally diverse natural products, a focused library featured by Michael acceptors is constructed with IBX mediated oxidation. Biological assay on five tumor cell lines indicates that four Michael acceptors, 8a, 11a, 12a, 14a, are with improved cytotoxicity (3-10 folds more potent than the parent compounds), which merit further investigations. Further thiol-sensitive assay of the active hit $\mathbf{8 a}$ revealed that it was an irreversible Michael acceptor. The results suggest that the strategy is not only effective and relatively high discovery rate $(28 \%)$, but also resource saving.
\end{abstract}

Keywords: drug leads identification, in-active natural products re-discovery, Michael acceptors, anti-tumor activity

\section{Introduction}

Drug-lead identification is the first step of drug discovery. A good start may set a success keynote for the whole process. So it is worthwhile to pay more attention on drug lead identification. Though plenty methods, including random screening, high-throughput screening from database, fragment based lead design and computer aided lead identification, are available for drug lead discovery ${ }^{1,2}$, some challenges remain un-addressed. The discovery efficiency and structure diversity are often low, and the leads are always hampered on the way to drug candidates. In one word, the lead quality is frequently unsatisfactory $^{3,4}$.

On the other hand, the abundant structure and function diversity fueled by natural products has provided a steady flow for the novel drugs. Many drugs used in clinic are natural products or compounds derived from natural products ${ }^{5-7}$. It is particularly true in anti-cancer and anti-infectious therapy field. We would like to dig out something valuable from this underestimated repository.

What's more, in the drug lead identification process, the major attentions are focused on the active hits, leaving vast amount of counterparts under-valued. And what shocks us most is that plenty of the "in-active" natural products are abundant in plants. So how to make sustainable use of these

\footnotetext{
*To whom correspondence should be addressed. E-mail: qinshizhao@mail.kib.ac.cn (Q.S. Zhao);

liyanb@mail.kib.ac.cn (Y. Li)
}

"in-active" natural products becomes a highly valuable project. We wonder that if we can turn the "trash" to the "treasure" by incorporation of pharmaceutically privileged structure moiety through some simple chemical transformations.

Based on the reasons mentioned above, we would like to combine the diverse natural products and the pharmaceutically privileged moiety together so as to identify novel drug leads. So what moiety will be chosen? The $\alpha, \beta$-unsaturated ketone moiety came to our sight and became our right choice.

It is generally believed that Michael acceptors form covalent bond with the active site cysteine of the proteases to solicit a biological effect ${ }^{8-11}$. The Cysteine proteases, including papains, cathepsins, calpains, caspases and lugumain, represent a biologically important clan of protein, which are important therapeutic target of tumor, inflammation and auto-immune disease $^{12-14}$. So it is no surprise that Michael acceptors have the potential of anti-tumor activity. In 2005, a Michael acceptor derived from oleanic acid, TP235, was approved as an orphan drug for treatment of pancreatic cancer and also used as an agent for treatment of diabetes associated chronic kidney disease in late clinical trial ${ }^{15,16}$. This discovery has provoked the keen interests in Michael acceptors. Since then, more and more successful examples in drug discovery spring up. A cruzain inhibitor, CRA-3386, was approved into clinical trial for treatment of Chagas disease ${ }^{17}$. Another Michael acceptor, AG7088, entered into clinical trial II for therapy of rhinovirus infection ${ }^{18}$. Schust $J$. et al. identified a novel Michael acceptor, static, as a selective STAT3 activation inhibitor from a compound library, and proved that the Michael acceptor moiety was its key pharmacophore (Figure 1) ${ }^{19}$. The pioneer work leads us to an idea that 
identification of novel drug leads from structurally diverse and functionally under-mined natural products by introduction Michael acceptor moiety.

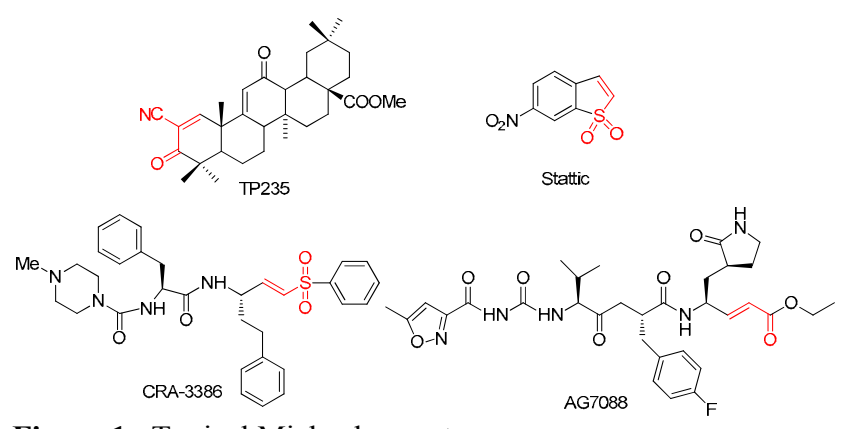

Figure 1. Typical Michael acceptors

With the idea in mind, we then started the execution of the plan. Though plenty of methods available in our chemical tool box, including $\mathrm{Pd}(\mathrm{OAc})_{2}$ catalyzed Saegusa oxidation ${ }^{20}$, benzeneselenenylation-oxidative elimination sequence ${ }^{21}$, both the methods require trivial operations and relative harsh reaction conditions. Fortunately, we have a newly invented method namely IBX mediated oxidation available ${ }^{22}$, which features with higher efficiency and simpler operations. The power of the method is not fully exemplified, especially in complex natural products.

Herein, we reported the construction of a small diversityoriented combinatorial library derived from natural products, which featured with $\alpha, \beta$-unsaturated carbonyl moiety using IBX mediated oxidation.

\section{Results and Discussion}

Starting from structurally diverse natural products, we prepared fourteen Michael acceptors efficiently (Table 1).

All the substrates and the Michael acceptors were evaluated on five human tumor cell lines, including HL-60, SMMC-7721, A-549, SK-BR-3 and PANC-1, using 3-(4,5-dimethylthiazol2-yl)-2,5-diphenyltetrazolium bromide (MTT) method. And anticancer drug cisplatin (DDP) was used as the positive control (Table 2).

As summarized in Table 2, four Michael acceptors, 8a, 11a and 12a, 14a, are found to be with significantly improved antitumor activity. Especially, compounds 8a and 12a exhibit single digit micro-molar inhibitory activity against HL-60, SK-BR-3 and PANC-1 cell lines, which are up to 10 times more potent than the corresponding parent compounds. It's also pleased to know that the parent compounds $\mathbf{8}$ and $\mathbf{1 2}$ are relatively abundant in plants, which are worthy of our further attentions.

Moreover, we also investigated the possible action mode of the active hit 8a in a thiol-sensitive assay using an NMR method, which was developed by Appendino G. et al ${ }^{23}$. The method was proved effective for identifying Michael acceptors, and sorting them into reversible and irreversible thiol sinks. Upon treatment of two equivalents of cysteamine, a known biologically relevant model thiol ${ }^{24}$, in deuterated DMSO, a Michael adduct of $\mathbf{8 b}$ was formed instantaneously (Figure 2), and the adduct was irreversible by diluting with $\mathrm{CDCl}_{3}$. The results reveal that the Michael acceptor moiety is the key pharmacophore of the active hit $\mathbf{8 a}$, and $\mathbf{8 a}$ is classified as the irreversible Michael acceptor accordingly.

In conclusion, a potential strategy to identify drug leads and re-discover the "trash" natural products is exemplified. The possible action mode of typical active hit 8a was also investigated. It was confirmed that the Michael acceptor moiety was the key pharmacophore and 8a was an irreversible thiol sink. And the superiority of the strategy is apparent, including resource saving, increased discovery rate, higher efficiency. Optimization process can be furthered based on the leads identified. Moreover, the strategy also provides an alternative view to evaluate the "trash" natural products, and may reward us serendipity.

Table 1. Preparation of Michael acceptors

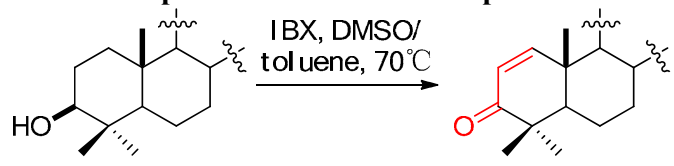

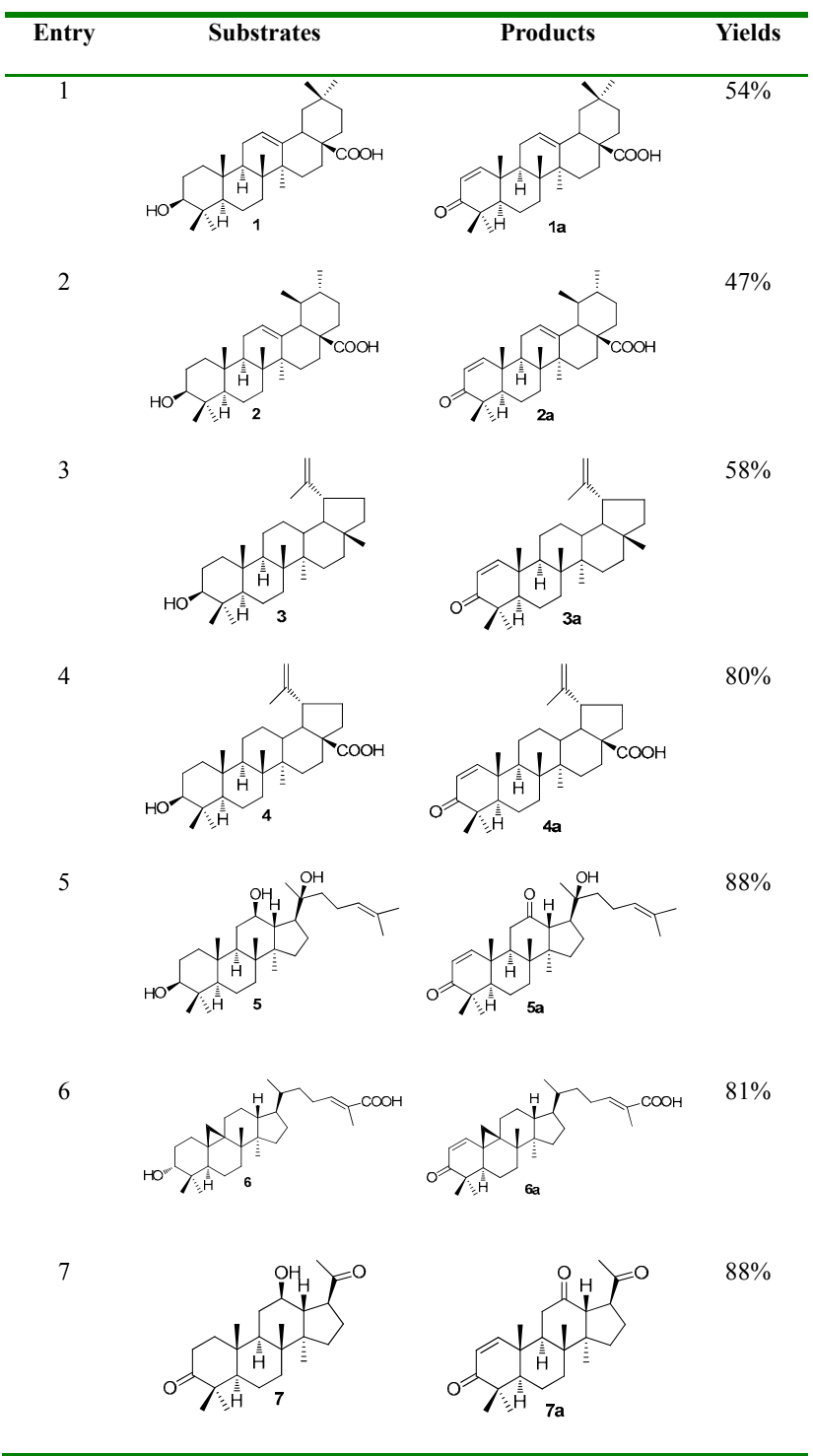




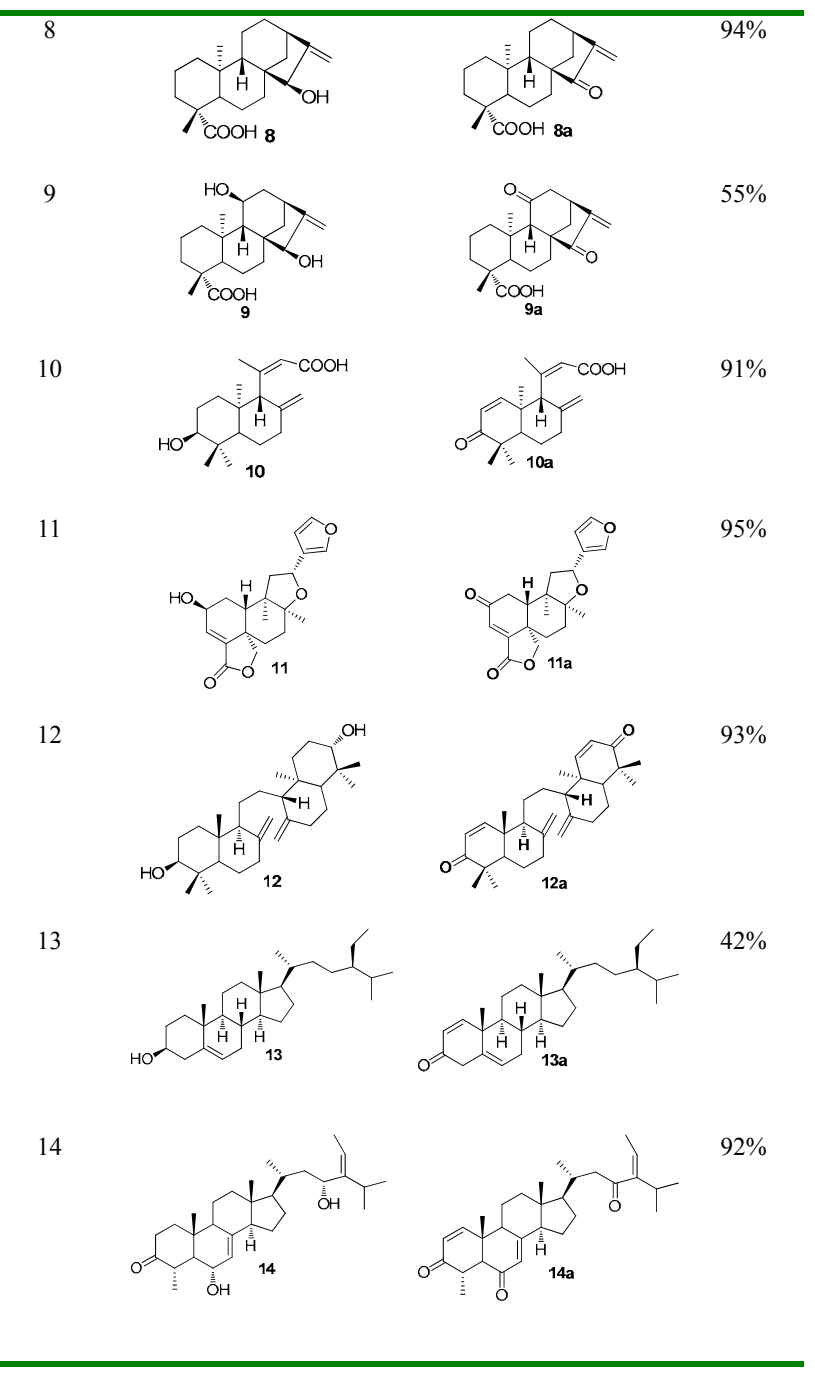

\section{Experimental Section}

Material and Methods. Reagents and solvents were used as commercial grade. Toluene and dimethyl sulfoxide (DMSO) were treated as anhydrous solvents prior to use. Chromatographies were performed with 300-400 mesh silica gels. Thin layer chromatographies were carried out on Merck silica plates $(0.25 \mathrm{~mm}$ layer thickness). ESIMS and HRESIMS were taken on a VG Auto Spec-3000 or on a Finnigan MAT 90 instrument. Optical rotations were measured with a Horiba SEPA-300 polarimeter. ${ }^{1} \mathrm{H}$ and ${ }^{13} \mathrm{C}$ NMR experiments were performed on a Bruker AM-300, AM-400 and DRX-500 NMR spectrometer at ambient temperature. And chemical shifts were given in $\delta$ with TMS as internal reference.

General Procedure for Preparation of Michael Acceptors $1 \mathbf{a}-14 \mathbf{a}^{16}$. To a solution of the substrate $(1.0 \mathrm{mmol})$ in DMSO/toluene $(0.8 \mathrm{~mL} / 0.2 \mathrm{~mL})$ was added IBX $(3.0 \mathrm{mmol})$ in one portion. The mixture was heated to $85-95{ }^{\circ} \mathrm{C}$, and was followed by TLC until no starting material was detected. Then the mixture was cooled to room temperature and diluted with $\mathrm{H}_{2} \mathrm{O}$. The aqueous layer was extracted with $\mathrm{Et}_{2} \mathrm{O}$ for three times. The combined organic layer was washed with $5 \%$
$\mathrm{NaHCO}_{3}(3 \times 10 \mathrm{~mL}), \mathrm{H}_{2} \mathrm{O}(1 \times 10 \mathrm{~mL})$, and dried $\left(\mathrm{MgSO}_{4}\right)$, followed by removal of solvent in vacuo, leading to crude compounds which was purified using flash column chromatography on silica gel.

Oleana-1,12-dien-3-oxo-28-oic acid (1a): white foam, ${ }^{1} \mathrm{H}$ NMR (500 MHz, $\left.\mathrm{CDCl}_{3}\right): \delta 7.06(\mathrm{~d}, J=10.1 \mathrm{~Hz}, 1 \mathrm{H}), 5.81(\mathrm{~d}$, $J=10.1 \mathrm{~Hz}, 1 \mathrm{H}), 5.31(\mathrm{~d}, J=3.7 \mathrm{~Hz}, 1 \mathrm{H}), 2.23(\mathrm{~d}, J=11.2$ $\mathrm{Hz}, 1 \mathrm{H}), 2.17-2.13(\mathrm{~m}, 1 \mathrm{H}), 2.09(\mathrm{~d}, J=3.9 \mathrm{~Hz}, 1 \mathrm{H}), 2.05$ (s, $1 \mathrm{H}), 2.01$ (dd, $J=13.5,4.2 \mathrm{~Hz}, 1 \mathrm{H}), 1.87$ (td, $J=13.5,4.2 \mathrm{~Hz}$, $1 \mathrm{H}), 1.80(\mathrm{dd}, J=11.4,6.0 \mathrm{~Hz}, 1 \mathrm{H}), 1.77-1.72(\mathrm{~m}, 1 \mathrm{H}), 1.68$ (dd, $J=13.2,3.6 \mathrm{~Hz}, 2 \mathrm{H}), 1.59-1.49(\mathrm{~m}, 4 \mathrm{H}), 1.46-1.39(\mathrm{~m}$, $2 \mathrm{H}), 1.38-1.28(\mathrm{~m}, 3 \mathrm{H}), 1.25(\mathrm{~d}, J=2.3 \mathrm{~Hz}, 1 \mathrm{H}), 1.21(\mathrm{dd}, J=$ 6.4, $2.1 \mathrm{~Hz}, 1 \mathrm{H}), 1.17$ (s, 3H), $1.14(\mathrm{~s}, 3 \mathrm{H}), 1.10$ (s, 3H), 1.07 $(\mathrm{s}, 3 \mathrm{H}), 0.95(\mathrm{~d}, J=6.2 \mathrm{~Hz}, 2 \mathrm{H}), 0.86(\mathrm{~s}, 3 \mathrm{H}) ;{ }^{13} \mathrm{C}$ NMR $(125$ $\left.\mathrm{MHz}, \mathrm{CDCl}_{3}\right) \delta 206.2(\mathrm{C}), 184.6(\mathrm{C}), 160.5(\mathrm{CH}), 139.9(\mathrm{C})$, $126.4(\mathrm{CH}), 55.9(\mathrm{C}), 54.8(\mathrm{CH}), 45.9(\mathrm{C}), 43.7(\mathrm{C}), 43.0(\mathrm{CH})$, $41.6(\mathrm{C}), 40.7(\mathrm{C}), 40.3(\mathrm{CH}), 40.1(\mathrm{CH}), 38.0\left(\mathrm{CH}_{2}\right), 34.1$ $\left(\mathrm{CH}_{2}\right), 31.9\left(\mathrm{CH}_{2}\right), 29.3\left(\mathrm{CH}_{2}\right), 29.2\left(\mathrm{CH}_{3}\right), 25.3\left(\mathrm{CH}_{2}\right), 24.8$ $\left(\mathrm{CH}_{3}\right), 24.6\left(\mathrm{CH}_{2}\right), 22.9\left(\mathrm{CH}_{3}\right), 22.4\left(\mathrm{CH}_{2}\right), 20.2\left(\mathrm{CH}_{2}\right), 20.1$ $\left(\mathrm{CH}_{3}\right), 18.9\left(\mathrm{CH}_{3}\right), 18.3\left(\mathrm{CH}_{3}\right)$; HREIMS $(\mathrm{m} / \mathrm{z}): 452.3283[\mathrm{M}]^{+}$ (calcd for $\mathrm{C}_{30} \mathrm{H}_{44} \mathrm{O}_{3}, 452.3290$ ).

Ursa-1,12-dien-3-oxo-28-oic acid (2a): white foam, ${ }^{1} \mathrm{H}$ NMR $\left(400 \mathrm{MHz}, \mathrm{CDCl}_{3}\right): \delta 7.06(\mathrm{~d}, J=10.1 \mathrm{~Hz}, 1 \mathrm{H}), 5.81(\mathrm{~d}$, $J=10.1 \mathrm{~Hz}, 1 \mathrm{H}), 5.31(\mathrm{~d}, J=3.7 \mathrm{~Hz}, 1 \mathrm{H}), 2.23(\mathrm{~d}, J=11.2$ $\mathrm{Hz}, 1 \mathrm{H}), 2.17-2.13(\mathrm{~m}, 1 \mathrm{H}), 2.09(\mathrm{~d}, J=3.9 \mathrm{~Hz}, 1 \mathrm{H}), 2.05(\mathrm{~s}$, $1 \mathrm{H}), 2.01(\mathrm{dd}, J=13.5,4.2 \mathrm{~Hz}, 1 \mathrm{H}), 1.87(\mathrm{td}, J=13.5,4.2 \mathrm{~Hz}$, $1 \mathrm{H}), 1.80(\mathrm{dd}, J=11.4,6.0 \mathrm{~Hz}, 1 \mathrm{H}), 1.77-1.72(\mathrm{~m}, 1 \mathrm{H}), 1.68$ (dd, $J=13.2,3.6 \mathrm{~Hz}, 2 \mathrm{H}), 1.59-1.49(\mathrm{~m}, 4 \mathrm{H}), 1.46-1.39(\mathrm{~m}$, $2 \mathrm{H}), 1.38-1.28(\mathrm{~m}, 3 \mathrm{H}), 1.25(\mathrm{~d}, J=2.3 \mathrm{~Hz}, 1 \mathrm{H}), 1.21(\mathrm{dd}, J=$ 6.4, $2.1 \mathrm{~Hz}, 1 \mathrm{H}), 1.17(\mathrm{~s}, 3 \mathrm{H}), 1.14(\mathrm{~s}, 3 \mathrm{H}), 1.10(\mathrm{~s}, 3 \mathrm{H}), 1.07$ $(\mathrm{s}, 3 \mathrm{H}), 0.95(\mathrm{~d}, J=6.2 \mathrm{~Hz}, 2 \mathrm{H}), 0.86(\mathrm{~s}, 3 \mathrm{H}) ;{ }^{13} \mathrm{C}$ NMR $(100$ $\left.\mathrm{MHz}, \mathrm{CDCl}_{3}\right) \delta 205.3(\mathrm{C}), 183.5(\mathrm{C}), 159.2(\mathrm{CH}), 138.5(\mathrm{C})$, $125.0(\mathrm{CH}), 53.3(\mathrm{CH}), 52.6(\mathrm{CH}), 48.0(\mathrm{C}), 44.4(\mathrm{C}), 43.0$ $(\mathrm{CH}), 42.2(\mathrm{C}), 41.5(\mathrm{CH}), 40.1(\mathrm{C}), 39.3(\mathrm{C}), 38.8(\mathrm{CH}), 38.7$ $(\mathrm{CH}), 36.5\left(\mathrm{CH}_{2}\right), 32.6\left(\mathrm{CH}_{2}\right), 30.6\left(\mathrm{CH}_{2}\right), 27.8\left(\mathrm{CH}_{2}\right), 27.8$ $\left(\mathrm{CH}_{3}\right), 23.9\left(\mathrm{CH}_{2}\right), 23.4\left(\mathrm{CH}_{3}\right), 23.1\left(\mathrm{CH}_{2}\right), 21.5\left(\mathrm{CH}_{3}\right), 21.0$ $\left(\mathrm{CH}_{3}\right), 18.7\left(\mathrm{CH}_{3}\right), 17.5\left(\mathrm{CH}_{3}\right), 16.9\left(\mathrm{CH}_{3}\right)$; HREIMS $(\mathrm{m} / \mathrm{z})$ : $452.3291[\mathrm{M}]^{+}$(calcd for $\mathrm{C}_{30} \mathrm{H}_{44} \mathrm{O}_{3}, 452.3290$ ).

Lupa-1,12,20(29)-trien-3-one (3a): white foam, ${ }^{1} \mathrm{H}$ NMR $\left(400 \mathrm{MHz}, \mathrm{CDCl}_{3}\right): \delta 7.09(\mathrm{~d}, J=10.2 \mathrm{~Hz}, 1 \mathrm{H}), 5.78(\mathrm{~d}, J=$ $10.2 \mathrm{~Hz}, 1 \mathrm{H}), 4.70(\mathrm{~d}, J=1.7 \mathrm{~Hz}, 1 \mathrm{H}), 4.58(\mathrm{~s}, 1 \mathrm{H}), 2.39$ (td, $J$ $=11.0,5.7 \mathrm{~Hz}, 1 \mathrm{H}), 2.04(\mathrm{~s}, 1 \mathrm{H}), 1.97-1.88(\mathrm{~m}, 1 \mathrm{H}), 1.72(\mathrm{~d}$, $J=4.2 \mathrm{~Hz}, 1 \mathrm{H}), 1.68(\mathrm{~s}, 3 \mathrm{H}), 1.67-1.59(\mathrm{~m}, 2 \mathrm{H}), 1.58(\mathrm{~s}, 1 \mathrm{H})$, $1.56-1.50(\mathrm{~m}, 4 \mathrm{H}), 1.47(\mathrm{dt}, J=9.4,3.9 \mathrm{~Hz}, 3 \mathrm{H}), 1.43-1.32$ $(\mathrm{m}, 5 \mathrm{H}), 1.24(\mathrm{~d}, J=4.1 \mathrm{~Hz}, 1 \mathrm{H}), 1.20(\mathrm{~d}, J=11.0 \mathrm{~Hz}, 1 \mathrm{H})$, $1.12(\mathrm{~s}, 3 \mathrm{H}), 1.10(\mathrm{~s}, 3 \mathrm{H}), 1.07(\mathrm{~s}, 3 \mathrm{H}), 1.06(\mathrm{~s}, 3 \mathrm{H}), 1.03-0.99$ $(\mathrm{m}, 1 \mathrm{H}), 0.95(\mathrm{~s}, 3 \mathrm{H}), 0.80(\mathrm{~s}, 3 \mathrm{H}) ;{ }^{13} \mathrm{C}$ NMR $(100 \mathrm{MHz}$, $\left.\mathrm{CDCl}_{3}\right) \delta 205.4(\mathrm{C}), 159.8(\mathrm{CH}), 150.6(\mathrm{C}), 125.1(\mathrm{CH}), 109.4$ $\left(\mathrm{CH}_{2}\right), 53.3(\mathrm{CH}), 48.0(\mathrm{CH}), 47.8(\mathrm{CH}), 44.5(\mathrm{C}), 44.3(\mathrm{CH})$, $43.0(\mathrm{C}), 42.9(\mathrm{C}), 41.7(\mathrm{C}), 39.9\left(\mathrm{CH}_{2}\right), 39.5(\mathrm{C}), 38.1(\mathrm{CH})$, $35.4\left(\mathrm{CH}_{2}\right), 33.7\left(\mathrm{CH}_{2}\right), 29.7\left(\mathrm{CH}_{2}\right), 27.7\left(\mathrm{CH}_{3}\right), 27.3\left(\mathrm{CH}_{2}\right)$, $25.0\left(\mathrm{CH}_{2}\right), 21.3(\mathrm{CH}), 21.1\left(\mathrm{CH}_{2}\right), 19.2(\mathrm{CH}), 19.1\left(\mathrm{CH}_{3}\right)$, $18.9\left(\mathrm{CH}_{2}\right), 17.9\left(\mathrm{CH}_{3}\right), 16.4\left(\mathrm{CH}_{3}\right), 14.3\left(\mathrm{CH}_{3}\right)$; HREIMS $(\mathrm{m} / \mathrm{z}): 422.3548[\mathrm{M}]^{+}$(calcd for $\left.\mathrm{C}_{30} \mathrm{H}_{46} \mathrm{O}, 422.3549\right)$.

Lupa-1,12,20(29)-trien-3-oxo-28-oic acid (4a): white foam, ${ }^{1} \mathrm{H}$ NMR $\left(500 \mathrm{MHz}, \mathrm{CDCl}_{3}\right): \delta 7.11(\mathrm{~d}, J=10.3 \mathrm{~Hz}$, $1 \mathrm{H}), 5.80(\mathrm{~d}, J=10.2 \mathrm{~Hz}, 1 \mathrm{H}), 4.76(\mathrm{~s}, 1 \mathrm{H}), 4.64(\mathrm{~s}, 1 \mathrm{H}), 3.03$ 
Table 2. In Vitro anti-tumor assay of the substrates and Michael acceptors

\begin{tabular}{|c|c|c|c|c|c|}
\hline \multirow[b]{2}{*}{ Entry } & \multicolumn{5}{|c|}{$\mathrm{IC}_{50}(\mu \mathrm{M})$} \\
\hline & HL- $60^{\mathrm{a}}$ & SMMC-7721 ${ }^{\mathrm{b}}$ & $\mathrm{A}-549^{\mathrm{c}}$ & SK-BR-3 ${ }^{\mathrm{d}}$ & PANC- $1^{\mathrm{e}}$ \\
\hline 1 & 14.99 & 14.28 & 14.75 & 13.51 & 14.17 \\
\hline $1 \mathrm{a}$ & 10.86 & 26.75 & 34.05 & $>40$ & $>40$ \\
\hline 2 & 15.23 & 15.73 & 16.77 & 14.93 & 15.12 \\
\hline $2 a$ & 9.25 & 20.35 & 34.05 & $>40$ & $>40$ \\
\hline 3 & $>40$ & $>40$ & $>40$ & $>40$ & $>40$ \\
\hline $3 \mathbf{a}$ & $>40$ & $>40$ & $>40$ & $>40$ & $>40$ \\
\hline 4 & 7.62 & 14.51 & 11.40 & 6.80 & 23.71 \\
\hline $4 a$ & 15.23 & 19.08 & 34.05 & $>40$ & $>40$ \\
\hline 5 & 14.99 & 28.99 & 26.75 & 16.04 & 15.25 \\
\hline $5 a$ & 15.98 & 26.32 & 25.90 & 18.53 & 18.68 \\
\hline 6 & $>40$ & $>40$ & $>40$ & $>40$ & $>40$ \\
\hline $6 \mathbf{a}$ & $>40$ & $>40$ & $>40$ & $>40$ & $>40$ \\
\hline 7 & $>40$ & $>40$ & $>40$ & $>40$ & $>40$ \\
\hline $7 \mathbf{a}$ & $>40$ & $>40$ & $>40$ & $>40$ & $>40$ \\
\hline 8 & $>40$ & $>40$ & $>40$ & $>40$ & $>40$ \\
\hline $8 \mathbf{a}$ & 6.39 & 6.59 & 12.76 & 14.46 & 17.58 \\
\hline 9 & $>40$ & $>40$ & $>40$ & $>40$ & $>40$ \\
\hline $9 a$ & $>40$ & $>40$ & $>40$ & $>40$ & $>40$ \\
\hline 10 & $>40$ & $>40$ & $>40$ & $>40$ & $>40$ \\
\hline $10 \mathrm{a}$ & $>40$ & $>40$ & $>40$ & $>40$ & $>40$ \\
\hline 11 & $>40$ & $>40$ & $>40$ & $>40$ & $>40$ \\
\hline $11 \mathrm{a}$ & 14.99 & 21.35 & $>40$ & 18.05 & 19.80 \\
\hline 12 & $>40$ & $>40$ & $>40$ & $>40$ & $>40$ \\
\hline $12 a$ & 6.59 & 10.18 & 12.16 & 4.92 & 3.76 \\
\hline 13 & $>40$ & $>40$ & $>40$ & $>40$ & $>40$ \\
\hline $13 a$ & $>40$ & $>40$ & $>40$ & $>40$ & $>40$ \\
\hline 14 & $>40$ & $>40$ & $>40$ & $>40$ & $>40$ \\
\hline $14 a$ & 12.55 & 14.05 & 16.51 & 13.63 & 12.13 \\
\hline $\mathrm{DDP}^{f}$ & 1.94 & 14.99 & 13.39 & 15.68 & 25.57 \\
\hline
\end{tabular}

${ }^{\mathrm{a}} \mathrm{HL}-60$, Human promyelocytic leukemia cell line; ' $\mathrm{SMMC}-7721$, human hepatocellular carcinoma cell line; ${ }^{\mathrm{c}} \mathrm{A}-549$, Human lung carcinoma cell line; ${ }^{\mathrm{d}} \mathrm{SK}-\mathrm{BR}-3$, Human breast adenocarcinoma cell line; ${ }^{\mathrm{e}} \mathrm{PANC}-1$, Human pancreatic carcinoma, epithelial-like cell line; ${ }^{\mathrm{h}} \mathrm{DDP}$ : cisplatin, which was used as the positive control.

$(\mathrm{dd}, J=10.7,6.0 \mathrm{~Hz}, 1 \mathrm{H}), 2.34-2.28(\mathrm{~m}, 1 \mathrm{H}), 2.26(\mathrm{dd}, J=$ 12.3, 3.2 Hz, 1H), 2.03-1.96 (m, 2H), 1.79 (d, $J=13.2 \mathrm{~Hz}$, $1 \mathrm{H}), 1.70(\mathrm{~s}, 3 \mathrm{H}), 1.65(\mathrm{t}, J=11.4 \mathrm{~Hz}, 2 \mathrm{H}), 1.60-1.56(\mathrm{~m}, 1 \mathrm{H})$ $1.56-1.50(\mathrm{~m}, 4 \mathrm{H}), 1.44(\mathrm{~m}, 5 \mathrm{H}), 1.26(\mathrm{~s}, 6 \mathrm{H}), 1.13(\mathrm{~s}, 3 \mathrm{H})$, $1.07(\mathrm{~s}, 3 \mathrm{H}), 1.06(\mathrm{~s}, 3 \mathrm{H}), 1.02(\mathrm{~s}, 3 \mathrm{H}), 1.00(\mathrm{~s}, 3 \mathrm{H}), 0.88(\mathrm{t}, J$ $=6.7 \mathrm{~Hz}, 1 \mathrm{H}) ;{ }^{13} \mathrm{C} \mathrm{NMR}\left(125 \mathrm{MHz} \mathrm{CDCl}_{3}\right) \delta 205.4(\mathrm{C})$, $181.5(\mathrm{C}), 160.5(\mathrm{CH}), 159.6(\mathrm{CH}), 150.1(\mathrm{C}), 125.1(\mathrm{CH})$, $109.8\left(\mathrm{CH}_{2}\right), 56.3(\mathrm{C}), 53.4(\mathrm{CH}), 49.1(\mathrm{CH}), 46.8(\mathrm{CH}), 44.6$ (C), $44.5(\mathrm{CH}), 42.7(\mathrm{C}), 41.6(\mathrm{C}), 39.5(\mathrm{C}), 38.6(\mathrm{CH}), 37.0$ $\left(\mathrm{CH}_{2}\right), 33.8\left(\mathrm{CH}_{2}\right), 32.1\left(\mathrm{CH}_{2}\right), 30.5\left(\mathrm{CH}_{2}\right), 29.6\left(\mathrm{CH}_{2}\right), 29.6$ $\left(\mathrm{CH}_{2}\right), 27.7\left(\mathrm{CH}_{2}\right), 25.4\left(\mathrm{CH}_{2}\right), 21.3\left(\mathrm{CH}_{3}\right), 21.1\left(\mathrm{CH}_{2}\right), 19.3$ $\left(\mathrm{CH}_{3}\right), 19.1\left(\mathrm{CH}_{3}\right), 18.9\left(\mathrm{CH}_{2}\right), 16.4\left(\mathrm{CH}_{3}\right), 14.5\left(\mathrm{CH}_{3}\right)$; HREIMS $(m / z): 452.3282[\mathrm{M}]^{+}$(calcd for $\left.\mathrm{C}_{30} \mathrm{H}_{44} \mathrm{O}_{3}, 452.3290\right)$.

Dammar-1,24(25)-dien-3,12-di-one (5a): white foam, ${ }^{1} \mathrm{H}$ NMR (500 MHz, $\left.\mathrm{CDCl}_{3}\right): \delta 6.94(\mathrm{~d}, J=10.3 \mathrm{~Hz}, 1 \mathrm{H}), 5.77$ (d, $J=10.2 \mathrm{~Hz}, 1 \mathrm{H}), 5.04$ (s, 1H), 2.85 (d, $J=10.3 \mathrm{~Hz}, 1 \mathrm{H}), 2.44$ (dd, $J=14.0,4.0 \mathrm{~Hz}, 1 \mathrm{H}), 2.35$ (dt, $J=13.7,6.6 \mathrm{~Hz}, 2 \mathrm{H}), 1.95$ (dd, $J=13.2,3.9 \mathrm{~Hz}, 2 \mathrm{H}), 1.77(\mathrm{dd}, J=21.8,11.4 \mathrm{~Hz}, 1 \mathrm{H})$, $1.62(\mathrm{~s}, 3 \mathrm{H}), 1.57(\mathrm{~d}, J=2.6 \mathrm{~Hz}, 1 \mathrm{H}), 1.55(\mathrm{~s}, 3 \mathrm{H}), 1.41(\mathrm{~d}, J$ $=13.4 \mathrm{~Hz}, 2 \mathrm{H}), 1.32-1.23(\mathrm{~m}, 2 \mathrm{H}), 1.22(\mathrm{~d}, J=4.1 \mathrm{~Hz}, 1 \mathrm{H})$, $1.20(\mathrm{~s}, 3 \mathrm{H}), 1.16(\mathrm{~s}, 1 \mathrm{H}), 1.10(\mathrm{~d}, J=3.1 \mathrm{~Hz}, 6 \mathrm{H}), 1.05$ (s, $6 \mathrm{H}), 1.00(\mathrm{~s}, 1 \mathrm{H}), 0.97(\mathrm{~s}, 1 \mathrm{H}) ;{ }^{13} \mathrm{C} \mathrm{NMR}\left(125 \mathrm{MHz}, \mathrm{CDCl}_{3}\right) \delta$ $212.0(\mathrm{C}), 204.5(\mathrm{C}), 157.1(\mathrm{CH}), 131.6(\mathrm{C}), 125.8(\mathrm{CH})$, $124.7(\mathrm{CH}), 73.2(\mathrm{C}), 56.4(\mathrm{CH}), 54.8(\mathrm{C}), 53.8(\mathrm{CH}), 47.4$ $(\mathrm{CH}), 45.7$ (CH), 44.7 (C), $41.0(\mathrm{C}), 39.7(\mathrm{C}), 39.0\left(\mathrm{CH}_{2}\right)$, $38.2\left(\mathrm{CH}_{2}\right), 33.4\left(\mathrm{CH}_{2}\right), 30.8\left(\mathrm{CH}_{2}\right), 27.6\left(\mathrm{CH}_{3}\right), 26.4\left(\mathrm{CH}_{3}\right)$, $25.7\left(\mathrm{CH}_{3}\right), 24.5\left(\mathrm{CH}_{2}\right), 22.5\left(\mathrm{CH}_{2}\right), 21.3\left(\mathrm{CH}_{3}\right), 19.0\left(\mathrm{CH}_{2}\right)$, $18.9\left(\mathrm{CH}_{3}\right), 17.6\left(\mathrm{CH}_{3}\right), 17.3\left(\mathrm{CH}_{3}\right), 16.1\left(\mathrm{CH}_{3}\right)$; HREIMS $(\mathrm{m} / \mathrm{z}): 454.3453[\mathrm{M}]^{+}$(calcd for $\left.\mathrm{C}_{30} \mathrm{H}_{46} \mathrm{O}_{3}, 454.3447\right)$.

9,19-Cyclolanost-1,24(25)-dien-3-oxo-26-oic acid (6a): white foam, ${ }^{1} \mathrm{H} \mathrm{NMR}\left(500 \mathrm{MHz}, \mathrm{CDCl}_{3}\right): \delta 6.90(\mathrm{t}, J=7.4 \mathrm{~Hz}$, $1 \mathrm{H}), 6.79(\mathrm{~d}, J=10.1 \mathrm{~Hz}, 1 \mathrm{H}), 6.73(\mathrm{~s}, \mathrm{OH}), 5.96(\mathrm{~d}, J=10.0$ $\mathrm{Hz}, 1 \mathrm{H}), 2.12(\mathrm{dd}, J=9.9,6.0 \mathrm{~Hz}, 2 \mathrm{H}), 2.02-1.95(\mathrm{~m}, 1 \mathrm{H})$, $1.90(\mathrm{dd}, J=12.9,7.4 \mathrm{~Hz}, 2 \mathrm{H}), 1.84(\mathrm{~s}, 3 \mathrm{H}), 1.71-1.49(\mathrm{~m}$, $7 \mathrm{H}), 1.44(\mathrm{~d}, J=9.2 \mathrm{~Hz}, 1 \mathrm{H}), 1.36-1.23(\mathrm{~m}, 6 \mathrm{H}), 1.10(\mathrm{~s}, 3 \mathrm{H})$, $0.96(\mathrm{~s}, 6 \mathrm{H}), 0.92(\mathrm{~d}, J=6.4 \mathrm{~Hz}, 3 \mathrm{H}), 0.89$ (s, 3H), 0.76 (d, $J$ $=4.6 \mathrm{~Hz}, 1 \mathrm{H}) ;{ }^{13} \mathrm{C} \mathrm{NMR}\left(125 \mathrm{MHz}, \mathrm{CDCl}_{3}\right) \delta 205.4(\mathrm{C}), 173.3$ (C), $154.1(\mathrm{CH}), 145.6(\mathrm{CH}), 126.6(\mathrm{CH}), 126.6(\mathrm{C}), 51.8$ (CH), 49.1 (C), $45.9(\mathrm{C}), 45.3(\mathrm{C}), 44.2(\mathrm{CH}), 43.5(\mathrm{CH}), 35.9$ $(\mathrm{CH}), 34.7\left(\mathrm{CH}_{2}\right), 34.4\left(\mathrm{CH}_{2}\right), 32.2\left(\mathrm{CH}_{2}\right), 29.8(\mathrm{C}), 29.1$ $\left(\mathrm{CH}_{2}\right), 27.8\left(\mathrm{CH}_{2}\right), 27.7\left(\mathrm{CH}_{2}\right), 25.8\left(\mathrm{CH}_{2}\right), 24.7(\mathrm{C}), 23.2$ $\left(\mathrm{CH}_{2}\right), 21.3\left(\mathrm{CH}_{3}\right), 19.4\left(\mathrm{CH}_{2}\right), 19.0\left(\mathrm{CH}_{3}\right), 18.4\left(\mathrm{CH}_{3}\right), 18.1$ $\left(\mathrm{CH}_{3}\right), 16.8\left(\mathrm{CH}_{3}\right), 11.9\left(\mathrm{CH}_{3}\right)$; HREIMS $(\mathrm{m} / \mathrm{z}): 452.3289[\mathrm{M}]^{+}$ (calcd for $\mathrm{C}_{30} \mathrm{H}_{44} \mathrm{O}_{3}, 452.3290$ ).

18-Norpregnane-1-en-3,12,20-tri-one (7a): white foam, ${ }^{1} \mathrm{H}$ NMR $\left(500 \mathrm{MHz} \mathrm{CDCl}_{3}\right): \delta 6.99(\mathrm{~d}, J=10.2 \mathrm{~Hz}, 1 \mathrm{H}), 5.82$ $(\mathrm{d}, J=10.2 \mathrm{~Hz}, 1 \mathrm{H}), 3.22(\mathrm{td}, J=10.7,6.9 \mathrm{~Hz}, 1 \mathrm{H}), 3.12(\mathrm{~d}, J$ $=10.5 \mathrm{~Hz}, 1 \mathrm{H}), 2.44(\mathrm{~d}, J=4.4 \mathrm{~Hz}, 1 \mathrm{H}), 2.41(\mathrm{~d}, J=13.1 \mathrm{~Hz}$, 1H), 2.22 (s, 3H), $2.21(\mathrm{~s}, 1 \mathrm{H}), 2.12-2.05$ (m, 1H), 1.97 (dd, $J$ $=12.8,4.4 \mathrm{~Hz}, 1 \mathrm{H}), 1.83(\mathrm{dd}, J=20.0,10.9 \mathrm{~Hz}, 1 \mathrm{H}), 1.73-$ $1.67(\mathrm{~m}, 2 \mathrm{H}), 1.65(\mathrm{~d}, J=2.8 \mathrm{~Hz}, 2 \mathrm{H}), 1.61(\mathrm{~d}, J=2.2 \mathrm{~Hz}$, 1H), $1.47(\mathrm{~d}, J=12.7 \mathrm{~Hz}, 1 \mathrm{H}), 1.30(\mathrm{~d}, J=9.8 \mathrm{~Hz}, 1 \mathrm{H}), 1.26$ $(\mathrm{s}, 3 \mathrm{H}), 1.23(\mathrm{~s}, 2 \mathrm{H}), 1.15(\mathrm{~s}, 3 \mathrm{H}), 1.14(\mathrm{~s}, 3 \mathrm{H}), 1.10(\mathrm{~s}, 3 \mathrm{H})$; ${ }^{13} \mathrm{C}$ NMR (125 MHz, $\left.\mathrm{CDCl}_{3}\right) \delta 210.4(\mathrm{C}), 208.5(\mathrm{C}), 204.6(\mathrm{C})$, $157.3(\mathrm{CH}), 125.7(\mathrm{CH}), 58.0(\mathrm{CH}), 54.3(\mathrm{C}), 53.7(\mathrm{CH}), 47.2$ $(\mathrm{CH}), 46.9(\mathrm{CH}), 44.7(\mathrm{C}), 40.9(\mathrm{C}), 39.7(\mathrm{C}), 38.5\left(\mathrm{CH}_{2}\right)$, $33.6\left(\mathrm{CH}_{2}\right), 31.2\left(\mathrm{CH}_{2}\right), 30.1\left(\mathrm{CH}_{3}\right), 29.6\left(\mathrm{CH}_{2}\right), 27.6\left(\mathrm{CH}_{3}\right)$, $25.6\left(\mathrm{CH}_{2}\right), 21.3\left(\mathrm{CH}_{3}\right), 18.9\left(\mathrm{CH}_{2}\right), 18.9\left(\mathrm{CH}_{3}\right), 17.0\left(\mathrm{CH}_{3}\right)$, $16.0\left(\mathrm{CH}_{3}\right)$; HREIMS $(\mathrm{m} / \mathrm{z}): 370.2516[\mathrm{M}]^{+}$(calcd for $\left.\mathrm{C}_{24} \mathrm{H}_{34} \mathrm{O}_{3}, 370.2516\right)$.

Kaur-16-en-15-oxo-18-oic acid (8a): white foam, ${ }^{1} \mathrm{H}$ NMR $\left(500 \mathrm{MHz} \mathrm{CDCl}_{3}\right): \delta 5.78(\mathrm{~s}, 1 \mathrm{H}), 5.14(\mathrm{~s}, 1 \mathrm{H}), 2.91(\mathrm{~s}, 1 \mathrm{H})$, $2.28(\mathrm{~d}, J=11.9 \mathrm{~Hz}, 1 \mathrm{H}), 2.00(\mathrm{~d}, J=13.1 \mathrm{~Hz}, 1 \mathrm{H}), 1.77$ (dd, $J=11.5,7.9 \mathrm{~Hz}, 1 \mathrm{H}), 1.70(\mathrm{ddd}, J=23.8,12.4,6.8 \mathrm{~Hz}, 5 \mathrm{H})$, 1.54 (dd, $J=15.4,5.8 \mathrm{~Hz}, 2 \mathrm{H}), 1.29$ (ddd, $J=16.6,13.1,6.0$ $\mathrm{Hz}, 3 \mathrm{H}), 1.21(\mathrm{dd}, J=10.3,3.2 \mathrm{~Hz}, 1 \mathrm{H}), 1.08(\mathrm{~s}, 3 \mathrm{H}), 1.03-$ $0.98(\mathrm{~m}, 1 \mathrm{H}), 0.88(\mathrm{~s}, 3 \mathrm{H}) ;{ }^{13} \mathrm{C} \mathrm{NMR}\left(125 \mathrm{MHz}, \mathrm{CDCl}_{3}\right) \delta$ $211.6(\mathrm{C}), 180.3(\mathrm{C}), 149.3(\mathrm{C}), 114.7(\mathrm{CH}), 55.8(\mathrm{CH}), 52.4$ (C), $51.5(\mathrm{CH}), 43.2(\mathrm{C}), 40.0(\mathrm{C}), 39.8\left(\mathrm{CH}_{2}\right), 37.8(\mathrm{CH})$, $37.6\left(\mathrm{CH}_{2}\right), 36.2\left(\mathrm{CH}_{2}\right), 33.4\left(\mathrm{CH}_{2}\right), 31.8\left(\mathrm{CH}_{2}\right), 28.6\left(\mathrm{CH}_{3}\right)$, $19.8\left(\mathrm{CH}_{2}\right), 18.6\left(\mathrm{CH}_{2}\right), 18.1\left(\mathrm{CH}_{2}\right), 15.2\left(\mathrm{CH}_{3}\right)$; HREIMS $(\mathrm{m} / \mathrm{z}): 316.2039[\mathrm{M}]^{+}$(calcd for $\left.\mathrm{C}_{20} \mathrm{H}_{28} \mathrm{O}_{3}, 316.2039\right)$.

Kaur-16-en-11,15-dioxo-18-oic acid (9a): ${ }^{1} \mathrm{H}$ NMR (500 


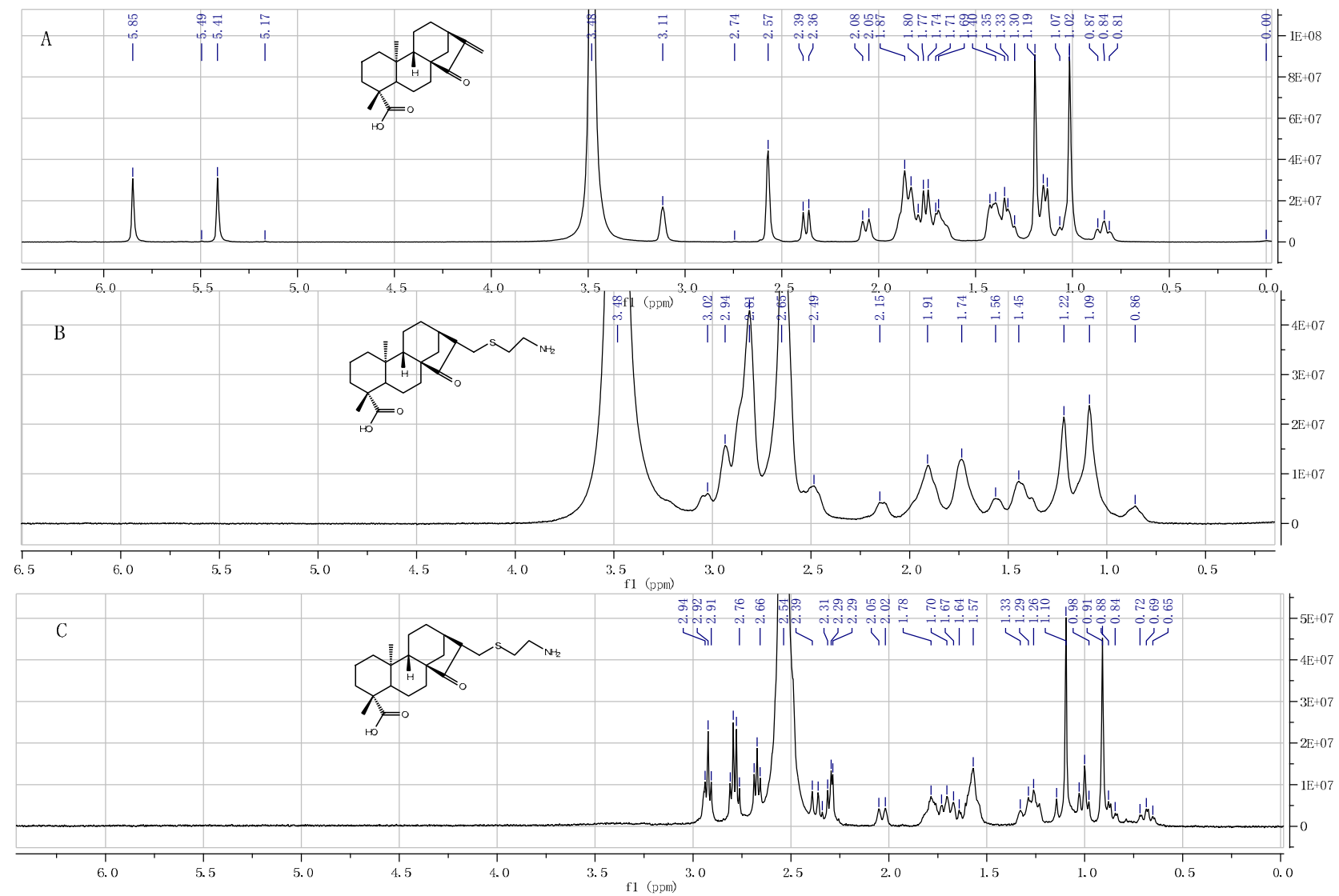

Figure 2. Reaction of compound 9a with cysteamine. A) ${ }^{1} \mathrm{H}$ NMR spectrum of 9a in $\left[\mathrm{D}_{6}\right]-\mathrm{DMSO}$; B) Spectrum recorded 5 min after the addition of 2 mol equiv cysteamine; C) Spectrum recorded 5 min after dilution (1:20) of the reaction mixture with $\mathrm{CDCl}_{3}$. All spectra were taken at $400 \mathrm{MHz}$. Note the complete and irreversible disappearance of the olefin signals at $\mathrm{d}=5.49 \mathrm{and} 5.41 \mathrm{ppm}$ (H-17a and $\mathrm{H}-17 \mathrm{~b}$ ) upon addition of cysteamine.

$\mathrm{MHz}, \mathrm{MeOD}) \delta 6.03(\mathrm{~s}, 1 \mathrm{H}), 5.42(\mathrm{~s}, 1 \mathrm{H}), 3.28(\mathrm{~s}, 1 \mathrm{H}), 2.82$ $(\mathrm{d}, J=12.5 \mathrm{~Hz}, 1 \mathrm{H}), 2.65(\mathrm{dd}, J=12.1,4.0 \mathrm{~Hz}, 1 \mathrm{H}), 2.57(\mathrm{~d}, J$ $=15.9 \mathrm{~Hz}, 1 \mathrm{H}), 2.20(\mathrm{~d}, J=9.6 \mathrm{~Hz}, 1 \mathrm{H}), 2.02(\mathrm{~m}, 1 \mathrm{H}), 1.97(\mathrm{~d}$, $J=14.0 \mathrm{~Hz}, 1 \mathrm{H}), 1.92(\mathrm{~s}, 1 \mathrm{H}), 1.89(\mathrm{~d}, J=3.6 \mathrm{~Hz}, 1 \mathrm{H}), 1.88$ $(\mathrm{s}, 1 \mathrm{H}), 1.80(\mathrm{~d}, J=13.9 \mathrm{~Hz}, 1 \mathrm{H}), 1.70-1.76(\mathrm{~m}, 2 \mathrm{H}), 1.59(\mathrm{~d}$, $J=10.2 \mathrm{~Hz}, 1 \mathrm{H}), 1.48(\mathrm{~d}, J=14.7 \mathrm{~Hz}, 1 \mathrm{H}), 1.29$ (s, 3H), 1.23 (s, $1 \mathrm{H}), 1.20(\mathrm{dd}, J=13.6,4.3 \mathrm{~Hz}, 1 \mathrm{H}), 1.09(\mathrm{dd}, J=13.5,4.1$ $\mathrm{Hz}, 1 \mathrm{H}), 1.02(\mathrm{~s}, 3 \mathrm{H}), 0.88(\mathrm{~m}, 1 \mathrm{H}) ;{ }^{13} \mathrm{C}$ NMR $(125 \mathrm{MHz}$, $\left.\mathrm{CDCl}_{3}\right) \delta 209.1(\mathrm{C}), 206.5(\mathrm{C}), 183.4(\mathrm{C}), 147.4(\mathrm{C}), 118.5$ $\left(\mathrm{CH}_{2}\right), 67.0(\mathrm{CH}), 55.4(\mathrm{CH}), 52.64(\mathrm{C}), 51.4\left(\mathrm{CH}_{2}\right), 43.8(\mathrm{C})$, $40.0(\mathrm{C}), 37.4\left(\mathrm{CH}_{2}\right), 36.5(\mathrm{CH}), 35.8\left(\mathrm{CH}_{2}\right), 32.0\left(\mathrm{CH}_{2}\right), 29.6$ $\left(\mathrm{CH}_{2}\right), 28.8\left(\mathrm{CH}_{3}\right), 19.8\left(\mathrm{CH}_{2}\right), 18.5\left(\mathrm{CH}_{2}\right), 17.1\left(\mathrm{CH}_{3}\right)$; HREIMS (m/z): $330.1833[\mathrm{M}]^{+}$(calcd for $\mathrm{C}_{20} \mathrm{H}_{26} \mathrm{O}_{4}, 330.1831$ ).

Labda-1,11-dien-3-oxo-13-oic acid (10a): white foam, ${ }^{1} \mathrm{H}$ $\operatorname{NMR}\left(500 \mathrm{MHz}, \mathrm{CDCl}_{3}\right): \delta 7.10(\mathrm{~d}, J=10.4 \mathrm{~Hz}, 1 \mathrm{H}), 5.97(\mathrm{~d}$, $J=10.4 \mathrm{~Hz}, 1 \mathrm{H}), 5.71(\mathrm{~s}, 1 \mathrm{H}), 5.03(\mathrm{~s}, 1 \mathrm{H}), 4.69(\mathrm{~s}, 1 \mathrm{H}), 2.51$ $(\mathrm{d}, J=13.0 \mathrm{~Hz}, 1 \mathrm{H}), 2.21(\mathrm{~s}, 3 \mathrm{H}), 2.17(\mathrm{~s}, 1 \mathrm{H}), 1.90(\mathrm{dd}, J=$ 20.1, 6.9 Hz, 2H), 1.73 (ddd, $J=17.8,15.0,8.4 \mathrm{~Hz}, 2 \mathrm{H}), 1.53$ (dd, $J=13.0,3.9 \mathrm{~Hz}, 1 \mathrm{H}), 1.16(\mathrm{~s}, 3 \mathrm{H}), 1.06(\mathrm{~s}, 3 \mathrm{H}), 0.92$ (s, $3 \mathrm{H})$.; ${ }^{13} \mathrm{C}$ NMR (125 MHz, $\left.\mathrm{CDCl}_{3}\right) \delta 204.6$ (C), $171.4(\mathrm{C})$, $162.6(\mathrm{C}), 155.7(\mathrm{CH}), 146.0(\mathrm{C}), 126.9(\mathrm{CH}), 115.1(\mathrm{CH})$, $109.3\left(\mathrm{CH}_{2}\right), 52.3(\mathrm{CH}), 51.3(\mathrm{CH}), 44.7(\mathrm{C}), 29.6(\mathrm{C}), 27.0$ $\left(\mathrm{CH}_{3}\right), 24.0\left(\mathrm{CH}_{2}\right), 22.0\left(\mathrm{CH}_{2}\right), 21.8\left(\mathrm{CH}_{3}\right), 19.2\left(\mathrm{CH}_{3}\right), 16.3$

\section{囪 Springer}

$\left(\mathrm{CH}_{3}\right)$; HREIMS $(\mathrm{m} / \mathrm{z})$ : $288.1724[\mathrm{M}]^{+}$(calcd for $\mathrm{C}_{18} \mathrm{H}_{24} \mathrm{O}_{3}$, 288.1725).

8,14-Secogammacera-1,8,14,19-tetra-en-3,21-di-one (11a): white foam, ${ }^{\mathrm{H}} \mathrm{H}$ NMR $\left(500 \mathrm{MHz}, \mathrm{CDCl}_{3}\right): \delta 7.10(\mathrm{~d}, J=10.4$ $\mathrm{Hz}, 1 \mathrm{H}), 5.97(\mathrm{~d}, J=10.4 \mathrm{~Hz}, 1 \mathrm{H}), 5.71(\mathrm{~s}, 1 \mathrm{H}), 5.03(\mathrm{~s}, 1 \mathrm{H})$, $4.69(\mathrm{~s}, 1 \mathrm{H}), 2.51(\mathrm{~d}, J=13.0 \mathrm{~Hz}, 1 \mathrm{H}), 2.21(\mathrm{~s}, 3 \mathrm{H}), 2.17(\mathrm{~s}$, 1H), 1.90 (dd, $J=20.1,6.9 \mathrm{~Hz}, 2 \mathrm{H}), 1.73$ (ddd, $J=17.8,15.0$, $8.4 \mathrm{~Hz}, 2 \mathrm{H}), 1.53(\mathrm{dd}, J=13.0,3.9 \mathrm{~Hz}, 1 \mathrm{H}), 1.16$ (s, 3H), 1.06 $(\mathrm{s}, 3 \mathrm{H}), 0.92(\mathrm{~s}, 3 \mathrm{H}) . ;{ }^{13} \mathrm{C}$ NMR $\left(125 \mathrm{MHz}, \mathrm{CDCl}_{3}\right) \delta 204.6$ (C), $171.4(\mathrm{C}), 162.6(\mathrm{C}), 155.7(\mathrm{CH}), 146.0(\mathrm{C}), 126.9(\mathrm{CH})$, $115.1(\mathrm{CH}), 109.3\left(\mathrm{CH}_{2}\right), 52.3(\mathrm{CH}), 51.3(\mathrm{CH}), 44.7(\mathrm{C}), 29.6$ (C), $27.0\left(\mathrm{CH}_{3}\right), 24.0\left(\mathrm{CH}_{2}\right), 22.0\left(\mathrm{CH}_{2}\right), 21.8\left(\mathrm{CH}_{3}\right), 19.2$ $\left(\mathrm{CH}_{3}\right), 16.3\left(\mathrm{CH}_{3}\right)$; HREIMS $(\mathrm{m} / \mathrm{z}): 342.1468[\mathrm{M}]^{+}$(calcd for $\left.\mathrm{C}_{20} \mathrm{H}_{22} \mathrm{O}_{5}, 342.1467\right)$.

8,14-Secogammacera-1,8,14,19-tetra-en-3,21-di-one (12a): white foam, ${ }^{\mathrm{T}} \mathrm{H}$ NMR $\left(500 \mathrm{MHz}, \mathrm{CDCl}_{3}\right): \delta 7.04(\mathrm{~d}, J=10.3$ $\mathrm{Hz}, 1 \mathrm{H}), 5.96$ (d, $J=10.3 \mathrm{~Hz}, 1 \mathrm{H}), 5.06(\mathrm{~s}, 1 \mathrm{H}), 4.79$ (s, 1H), $2.55(\mathrm{~d}, J=12.9 \mathrm{~Hz}, 1 \mathrm{H}), 2.09(\mathrm{t}, J=10.6 \mathrm{~Hz}, 1 \mathrm{H}), 1.97-1.84$ $(\mathrm{m}, 2 \mathrm{H}), 1.80(\mathrm{~d}, J=10.1 \mathrm{~Hz}, 2 \mathrm{H}), 1.61(\mathrm{~s}, 2 \mathrm{H}), 1.55(\mathrm{dd}, J=$ $13.0,4.1 \mathrm{~Hz}, 1 \mathrm{H}), 1.48(\mathrm{~d}, J=7.4 \mathrm{~Hz}, 1 \mathrm{H}), 1.27(\mathrm{~s}, 2 \mathrm{H})$, 1.18(s, 3H), 1.07 (s, 3H), $0.90(\mathrm{~s}, 3 \mathrm{H}) . ;{ }^{13} \mathrm{C}$ NMR $(125 \mathrm{MHz}$, $\left.\mathrm{CDCl}_{3}\right) \delta 204.7(\mathrm{C}), 156.1(\mathrm{CH}), 146.5(\mathrm{C}), 126.8(\mathrm{CH}), 109.4$ $\left(\mathrm{CH}_{2}\right), 52.3(\mathrm{CH}), 52.2(\mathrm{CH}), 44.6(\mathrm{C}), 41.4(\mathrm{C}), 37.7\left(\mathrm{CH}_{2}\right)$, 
29. $6(\mathrm{C}), 27.0\left(\mathrm{CH}_{3}\right), 24.0\left(\mathrm{CH}_{2}\right), 22.8\left(\mathrm{CH}_{2}\right), 21.7\left(\mathrm{CH}_{3}\right)$, $16.4\left(\mathrm{CH}_{3}\right)$; HREIMS $(\mathrm{m} / \mathrm{z})$ : $434.3173[\mathrm{M}]^{+}$(calcd for $\left.\mathrm{C}_{30} \mathrm{H}_{42} \mathrm{O}_{2}, 434.3173\right)$.

Stigmasta-1,5-dien-3-one (13a): white foam, ${ }^{1} \mathrm{H}$ NMR $\left(400 \mathrm{MHz}, \mathrm{CDCl}_{3}\right): \delta 6.15(\mathrm{~d}, J=11.0 \mathrm{~Hz}, 1 \mathrm{H}), 6.09(\mathrm{dd}, J=$ 9.8, $2.4 \mathrm{~Hz}, 1 \mathrm{H}), 5.67(\mathrm{~s}, 1 \mathrm{H}), 2.60-2.55(\mathrm{~m}, 1 \mathrm{H}), 2.54(\mathrm{~d}, J=$ $5.3 \mathrm{~Hz}, 1 \mathrm{H}), 2.45(\mathrm{~d}, J=3.7 \mathrm{~Hz}, 1 \mathrm{H}), 2.41(\mathrm{~d}, J=5.6 \mathrm{~Hz}, 1 \mathrm{H})$, $2.19(\mathrm{t}, J=10.3 \mathrm{~Hz}, 1 \mathrm{H}), 2.08(\mathrm{~d}, J=3.2 \mathrm{~Hz}, 1 \mathrm{H}), 2.06-2.03$ (m, 1H), 2.03-1.97 (m, 1H), 1.95-1.87 (m, 1H), 1.73-1.69 (m, 1H), $1.69-1.65(\mathrm{~m}, 1 \mathrm{H}), 1.61(\mathrm{~s}, 3 \mathrm{H}), 1.55-1.50(\mathrm{~m}, 1 \mathrm{H}), 1.45$ $(\mathrm{d}, J=3.7 \mathrm{~Hz}, 1 \mathrm{H}), 1.40(\mathrm{dd}, J=13.0,3.7 \mathrm{~Hz}, 2 \mathrm{H}), 1.34(\mathrm{~d}, J$ $=12.8 \mathrm{~Hz}, 2 \mathrm{H}), 1.30(\mathrm{~d}, J=7.7 \mathrm{~Hz}, 2 \mathrm{H}), 1.27-1.13(\mathrm{~m}, 12 \mathrm{H})$, $1.11(\mathrm{~s}, 3 \mathrm{H}), 1.05-0.99(\mathrm{~m}, 2 \mathrm{H}), 0.94(\mathrm{t}, J=6.3 \mathrm{~Hz}, 3 \mathrm{H}), 0.87$ $(\mathrm{s}, 3 \mathrm{H}), 0.85(\mathrm{~s}, 3 \mathrm{H}), 0.83(\mathrm{~d}, J=2.3 \mathrm{~Hz}, 3 \mathrm{H}), 0.81(\mathrm{~d}, J=2.7$ $\mathrm{Hz}, 3 \mathrm{H}), 0.76(\mathrm{~d}, J=4.6 \mathrm{~Hz}, 3 \mathrm{H}), 0.71(\mathrm{~s}, 1 \mathrm{H}) ;{ }^{13} \mathrm{C}$ NMR $(100$ $\left.\mathrm{MHz}, \mathrm{CDCl}_{3}\right) \delta 199.7(\mathrm{C}), 164.0(\mathrm{C}), 141.6(\mathrm{CH}), 127.7(\mathrm{CH})$, $123.4(\mathrm{CH}), 55.8(\mathrm{CH}), 53.3(\mathrm{CH}), 50.6(\mathrm{CH}), 45.7(\mathrm{CH}), 43.3$ (C), $39.4\left(\mathrm{CH}_{2}\right), 37.7(\mathrm{CH}), 36.1(\mathrm{CH}), 33.9\left(\mathrm{CH}_{2}\right), 33.8\left(\mathrm{CH}_{2}\right)$, $33.8\left(\mathrm{CH}_{2}\right), 29.0(\mathrm{CH}), 28.1\left(\mathrm{CH}_{2}\right), 26.0\left(\mathrm{CH}_{2}\right), 23.6\left(\mathrm{CH}_{2}\right)$, $23.0\left(\mathrm{CH}_{2}\right), 20.6\left(\mathrm{CH}_{2}\right), 19.7\left(\mathrm{CH}_{3}\right), 18.9\left(\mathrm{CH}_{3}\right), 18.6\left(\mathrm{CH}_{3}\right)$, $16.2\left(\mathrm{CH}_{3}\right), 11.9\left(\mathrm{CH}_{3}\right), 11.8\left(\mathrm{CH}_{3}\right)$; HREIMS $(\mathrm{m} / \mathrm{z}): 410.3546$ $[\mathrm{M}]^{+}$(calcd for $\mathrm{C}_{29} \mathrm{H}_{46} \mathrm{O}, 410.3549$ ).

Stigmasta-4-methyl-1,7(8),24(28)-triene-3,6,23-tri-one (14a): white foam, ${ }^{1} \mathrm{H}$ NMR $\left(400 \mathrm{MHz}, \mathrm{CDCl}_{3}\right): \delta 6.15$ (d, $J=11.0$ $\mathrm{Hz}, 1 \mathrm{H}), 6.09$ (dd, $J=9.8,2.4 \mathrm{~Hz}, 1 \mathrm{H}), 5.67(\mathrm{~s}, 1 \mathrm{H}), 2.60$ $2.55(\mathrm{~m}, 1 \mathrm{H}), 2.54(\mathrm{~d}, J=5.3 \mathrm{~Hz}, 1 \mathrm{H}), 2.45(\mathrm{~d}, J=3.7 \mathrm{~Hz}$, $1 \mathrm{H}), 2.41(\mathrm{~d}, J=5.6 \mathrm{~Hz}, 1 \mathrm{H}), 2.19(\mathrm{t}, J=10.3 \mathrm{~Hz}, 1 \mathrm{H}), 2.08$ $(\mathrm{d}, J=3.2 \mathrm{~Hz}, 1 \mathrm{H}), 2.06-2.03(\mathrm{~m}, 1 \mathrm{H}), 2.03-1.97(\mathrm{~m}, 1 \mathrm{H})$, $1.95-1.87(\mathrm{~m}, 1 \mathrm{H}), 1.73-1.69(\mathrm{~m}, 1 \mathrm{H}), 1.69-1.65(\mathrm{~m}, 1 \mathrm{H})$, $1.61(\mathrm{~s}, 3 \mathrm{H}), 1.55-1.50(\mathrm{~m}, 1 \mathrm{H}), 1.45(\mathrm{~d}, J=3.7 \mathrm{~Hz}, 1 \mathrm{H}), 1.40$ $(\mathrm{dd}, J=13.0,3.7 \mathrm{~Hz}, 2 \mathrm{H}), 1.34(\mathrm{~d}, J=12.8 \mathrm{~Hz}, 2 \mathrm{H}), 1.30(\mathrm{~d}, J$ $=7.7 \mathrm{~Hz}, 2 \mathrm{H}), 1.27-1.13(\mathrm{~m}, 12 \mathrm{H}), 1.11(\mathrm{~s}, 3 \mathrm{H}), 1.05-0.99(\mathrm{~m}$, 2H), $0.94(\mathrm{t}, J=6.3 \mathrm{~Hz}, 3 \mathrm{H}), 0.87(\mathrm{~s}, 3 \mathrm{H}), 0.85(\mathrm{~s}, 3 \mathrm{H}), 0.83$ $(\mathrm{d}, J=2.3 \mathrm{~Hz}, 3 \mathrm{H}), 0.81(\mathrm{~d}, J=2.7 \mathrm{~Hz}, 3 \mathrm{H}), 0.76(\mathrm{~d}, J=4.6$ $\mathrm{Hz}, 3 \mathrm{H}), 0.71(\mathrm{~s}, 1 \mathrm{H}) ;{ }^{13} \mathrm{C}$ NMR $\left(100 \mathrm{MHz}, \mathrm{CDCl}_{3}\right) \delta 202.7$ (C), 200.7 (C), $198.1(\mathrm{C}), 160.4(\mathrm{C}), 152.2(\mathrm{CH}), 148.5(\mathrm{C})$, $135.1(\mathrm{CH}), 127.3(\mathrm{CH}), 123.8(\mathrm{CH}), 55.8(\mathrm{CH}), 53.3(\mathrm{CH})$, $50.6(\mathrm{CH}), 45.7(\mathrm{CH}), 43.3(\mathrm{C}), 39.4\left(\mathrm{CH}_{2}\right), 37.7(\mathrm{CH}), 36.1$ (CH), $33.9\left(\mathrm{CH}_{2}\right), 33.8\left(\mathrm{CH}_{2}\right), 33.8\left(\mathrm{CH}_{2}\right), 29.0(\mathrm{CH}), 28.1$ $\left(\mathrm{CH}_{2}\right), 26.0\left(\mathrm{CH}_{2}\right), 23.6\left(\mathrm{CH}_{2}\right), 23.0\left(\mathrm{CH}_{2}\right), 20.6\left(\mathrm{CH}_{2}\right), 19.7$ $\left(\mathrm{CH}_{3}\right), 18.9\left(\mathrm{CH}_{3}\right), 18.6\left(\mathrm{CH}_{3}\right), 16.2\left(\mathrm{CH}_{3}\right), 11.9\left(\mathrm{CH}_{3}\right), 11.8$ $\left(\mathrm{CH}_{3}\right)$; HREIMS $(\mathrm{m} / \mathrm{z}): 450.3136[\mathrm{M}]^{+}$(calcd for $\mathrm{C}_{30} \mathrm{H}_{42} \mathrm{O}_{3}$, 450.3134).

Thiol Sensitive Assay. Compound 8a (10 mg, $0.03 \mathrm{mmol}$ ) was dissolved in $d_{6}$-DMSO $(500 \mu \mathrm{L})$ in a $5 \mathrm{~mm}$ NMR tube, and the spectrum was recorded (Figure 2A). Cysteamine (4.7 $\mathrm{mg}, 0.06 \mathrm{mmol}, 2 \mathrm{~mol}$ equiv) was then added, and the spectrum was recorded $5 \mathrm{~min}$ after the addition (Figure 2B). An aliquot $(25 \mu \mathrm{L})$ of the solution was then transferred into a second NMR tube containing $\mathrm{CDCl}_{3}(500 \mu \mathrm{L})$ and a new spectrum was recorded (Figure 2C). A positive result was evidenced by the disappearance of a particular olefin system of the substrate, and the irreversibility of the Michael addition by its disappearance upon dilution 1:20 with $\mathrm{CDCl}_{3}$.

Biological Assay. The used cell lines were human promyelocytic leukemia cell line (HL-60), human hepatocellular carcinoma cell line (SK-BR-3), human lung carcinoma cell line (A-549), human breast adenocarcinoma cell line (SMMC7721), human pancreatic carcinoma cell line (PANC-1). An MTT [3-(4,5-dimethylthiazol-2-yl)-2,5-diphenyltetrazolium bromide] colorimetric assay was performed in 96-well plates. HL-60 cells at the log phase of their growth cycle $\left(1.25 \times 10^{5}\right.$ cell $/ \mathrm{mL})$ were added to each well $(90 \mathrm{~mL} /$ well $)$, then treated in four replicates at various concentrations of the samples (1-100 $\mu \mathrm{g} / \mathrm{mL}$ ), and incubated for 48 hours at $37^{\circ} \mathrm{C}$ in a humidified atmosphere of $5 \% \mathrm{CO}_{2}$. After $48 \mathrm{~h}, 10 \mu \mathrm{L}$ of MTT solution (5 $\mathrm{mg} / \mathrm{mL}$ ) per well was added to each cultured medium, which were incubated for further 4 hours. Then, a three-system solution of $10 \%$ SDS- $5 \%$ isobutanole $-0.012 \mathrm{~mol} / \mathrm{L}$ hydrochloric acid was added to each well $(100 \mu \mathrm{L} /$ well $)$. After $12 \mathrm{~h}$ at room temperature, the OD of each well was measured on a Microplate Reader (BIO-TEK instruments Inc EL311S) at a wavelength of $570 \mathrm{~nm}$. In these experiments, the negative reference agents was $0.1 \%$ DMSO, and cisplatin (DDP) was used as the positive control with concentration of $1-80 \mu \mathrm{g} / \mathrm{mL}$. The same method was used in cytotoxic testing against SKBR-3, A549, SMMC-7721 and PANC-1 cell lines.

\section{Electronic Supplementary Material}

Supplementary material is available in the online version of this article at http://dx.doi.org/ 10.1007/s13659-012-0071-7 and is accessible for authorized users.

\section{Acknowledgments}

We thanked Mrs. Li-Yan Peng, Dr. Juan He, Dr. ZhengHong Pan, Dr. Xing-De Wu and Mr. Liao-Bin Dong for generously providing samples of natural products. We thanked the National Natural Science Foundation of China (No. 90813004, U0932602, 20802083 and 973 Program No. 2009CB522303 and No. 2011CB915503) and the State Key Laboratory of Phytochemistry and Plant Resources in West China (P2010-ZZ18) for financial support.

Open Access This article is distributed under the terms of the Creative Commons Attribution License which permits any use, distribution, and reproduction in any medium, provided the original author(s) and source are credited.

\section{References}

[1] Fattori, D.; Squarcia, A.; Bartoli, S. Drugs in R\&D 2008, 9, $217-$ 227.

[2] Xiang, M.; Cao, Y.; Fan, W.; Chen, L.; Mo, Y. Comb. Chem. High Throughput Screening 2012, 15, 328-337.

[3] Mestres, J.; Veeneman, G. H. J. Med. Chem. 2003, 46, 3441

[4] Gribbon, P.; Andreas, S. Drug Discov. Today 2005, 10, 17-22.

[5] Clardy, J.; Walsh, C. Nature 2004, 432, 829-837.

[6] Newman, D. J.; Cragg, G. M. J. Nat. Prod. 2007, 70, 461-477.

[7] Danishefsky, S. Nat. Prod. Rep. 2010, 27, 1114-1116.

[8] Aptula, A. O.; Roberts, D. W. Chem. Res. Toxicol. 2006, 19, $1097-1105$

[9] Amslinger, S. ChemMedChem 2010, 5, 351-356.

[10] Garuti, L.; Roberti, M.; Bottegoni, G. Curr. Med. Chem. 2011, 18, 2981-2994.

[11] Couch, R. D.; Browning, R. G.; Honda, T.; Gribble, G. W.; Wright, D. L.; Sporn, M. B.; Anderson, A. C. Bioorg. Med. Chem. Lett. 2005, 15, 2215-2219.

[12] Barrett, A. J.; Rawlings, N. D.; O'Brien, E. A. J. Struct. Biol. 2001, 134, 95-102.

\section{照 Springer}


[13] Leloup, L.; Wells, A. Expert Opin. Ther. Targets 2011, 15, 309323.

[14] Otto, H. H.; Schirmeister, T. Chem. Rev. 1997, 97, 133-172.

[15] Petronelli, A.; Pannitteri, G.; Testa, U. Anti-Cancer Drugs 2009, $20,880-892$.

[16] Dinkova-Kostova, A. T.; Liby, K. T.; Stephenson, K. K.; Holtzclaw, W. D.; Gao, X.; Suh, N.; Williams, C.; Risingsong, R.; Honda, T.; Gribble, G. W.; Sporn, M. B.; Talalay, P. Proc. Natl. Acad. Sci. USA 2005, 102, 4584-4589.

[17] Shenai, B. R.; Lee, B. J.; Alvarez-Hernandez, A.; Chong, P. Y.; Emal, C. D.; Neitz, R. J.; Roush, W. R.; Rosenthal, P. J. Antimicrob. Agents Ch. 2003, 47, 154-160.

[18] Ekici, O. D.; Li, Z. Z.; Campbell, A. J.; James, K. E.; Asgian, J. L.; Mikolajczyk, J.; Salvesen, G. S.; Ganesan, R.; Jelakovic, S.; Gruetter, M. G.; Powers, J. C. J. Med. Chem. 2006, 49, 57285749 .
[19] Schust, J.; Sperl, B.; Hollis, A.; Mayer, T. U.; Berg, T. Chem. Biol. 2006, 13, 1235-1242.

[20] Ito, Y.; Hirao, T.; Saegusa, T. J. Org. Chem. 1978, 43, 10111013.

[21] Reich, H. J.; Renga, J. M.; Reich, I. L. J. Am. Chem. Soc. 1975 97, 5434-5447.

[22] Nicolaou, K. C.; Montagnon, T.; Baran, P. S.; Zhong, Y. L. J. Am. Chem. Soc. 2002, 124, 2245-2258.

[23] Avonto, C.; Taglialatela-Scafati, O.; Pollastro, F.; Minassi, A.; Di Marzo, V.; De Petrocellis, L.; Appendino, G. Angew. Chem. Int. Ed. 2011, 50, 467-471.

[24] Torres, J. L.; Lozano, C.; Julià, L.; Sánchez-Baeza, F. J.; Anglada, J. M.; Centelles, J. J.; Cascante, M. Bioorg. Med. Chem. 2002, 10, 2497-2509. 